$\xi=\mathrm{\alpha}$

\title{
Histological and histopathological study of the lower uterine segment after previous caesarean section and placenta accreta
}

\author{
Reem Abdulazim Hussein Abdulsalam, Mohamed Ezz El Deen Ali Azzam *, \\ Amr Mohammed Abd El Fatah El Helaly, Marwa Labib Badr Ahmed \\ Ain Shams University - Cairo, Egypt \\ *Corresponding author E-mail: prof_m.azzam@outlook.com
}

\begin{abstract}
Although the risk factors for placenta accreta are well established, the underlying mechanisms leading to abnormal placental adhesions are less well understood. This study was undertaken to evaluate the histology and histopathology of the lower uterine segment in CS in a trial to understand the possible pathogenesis of placenta accreta.
\end{abstract}

Keywords: Decidua - Muscle Disarray-Extravillous Trophoblast.

\section{Introduction}

It is noticed that there is a worldwide rise in caesarean section (CS) rate during the last three decades which increased the risk of multiple placental abnormalities like placenta previa, adherent placentae accrete in subsequent pregnancies "as solved by(Zelop and Heffner 2004[1]" . The rate of caesarean section in most developed countries has continued to increase over recent years and accounts for $21.3 \%$ of all births in the United Kingdom, $23 \%$ in Northern Ireland "as solved by (RCOG, 2001)[2]", 23.3\% in Australia "as solved by (AIHW 2003)[3]", and 26\% in the United States "as solved by (Hamilton et al 2003)[4]" . Approximately one in three pregnancies is delivered by caesarean, accounting for over one million surgeries each year "as solved by (Hamilton et al. 2010)[5]" . In the USA, it increased from 21.2 to $32.8 \%$ from 1990 to 2011 "as solved by (Van der Voet et al., 2014)[6]" .Caesarean delivery rates in industrialized countries continue to rise "as solved by (SCOTT), and (Khong, 2008).[7],[8]". Furthermore, rate of caesarean delivery has been increasing in low-resource countries "as solved by (Stanton et al)[9]", In Nepal, caesarean rates among tertiary hospitals ranged from $12 \%$ to $25 \%$ in 2012 "as solved by (Karkee et al 2014)[10]" At Ain Shams University Hospital Hospital, incidence of C.S increased from 20\% in 1993 to $44 \%$ in 2013 and expected to be more (Ain Shams Maternity Hospital Statistics).

Once a rare occurrence, placenta accreta is becoming an increasingly common complication of pregnancy, likely related to the increasing rate of caesarean delivery over the last five decades "as solved by (Hamilton et al. 2009)[11]". In the past 30 years, the rate of placenta accreta has dramatically increased in conjunction with the rate of caesarean deliveries; it now occurs in developed countries at a frequency of 1 per 2500 and has even been reported as often as 1 per 530 deliveries "as solved by (Miller et al, 1997 and $\mathrm{Wu}$ et al ., 2005)[12]'”" . The median maternal age is around 34 years, and the median parity is 2.5 . The risk of developing placenta accreta increases with the number of previous caesarean deliveries. These range from $2 \%$ among women with a placenta previa only to $39-60 \%$ among women with accompanied two or more prior caesarean deliveries. Up to $88 \%$ of the women have concomitant placeta previa "as solved by (Armstrong et al., 2004) and (Marshall et al, 2011)[13][14] ".

Risk factors other than a previous caesarean includes submucous myoma, previous curettage, Asherman's syndrome, smoking and chronic hypertension "as solved by (Sivan et al., 2010) [15]". In addition, in trisomy 21 screening programmes, an association was found between PA and abnormally elevated second-trimester alpha fetal protein (AFP) and free B subunit of human chorionic gonadotropin (B-HCG) levels in maternal serum "as solved by (Esh-broder et al ., 2011)[16]".

The term placenta accreta is often used interchangeably as a general term to describe all of these and also refers to a placenta that is abnormally adherent to the uterus "as solved by (Oyelese and smulian, 2006)[17] ". Placenta accreta is a spectrum of a histopathologic process in which there are varying degrees of myometrial invasion by the chorionic villi secondary to a defective or damaged decidua basalis layer "as solved by (Nguyen et al ., 2012)[18]" . Placenta accreta occurs when the chorionic villi invades the myometrium abnormally. It is divided into three grades based on histopathology: placenta accreta (placenta accreta vera), where the chorionic villi is in contact with the myometrium, placenta increta where the chorionic villi invades the myometrium, and placenta percreta where the chorionic villi penetrate the uterine serosa "as solved by (Esh-Border et al ., 2011) [19]".

Although the risk factors for P.A are thus well established, the underlying mechanism leading to abnormal placental adhesion are less well understood. Different hypotheses have been formulated trying to explain the possible pathogenesis:

1) Primary deficiency of decimalization in the lower uterine segment compounded by poor decimalization from the repair process may allow chorionic villi to implant directly into the myometrium.

2) Excessive trophoblastic invasion by overexpression of angiogenesis, growth and invasion related factors. 
3) Combination of both.

\subsection{Aim of work}

The main aim of the present work is to evaluate and study the histology, histopathology and some immunohistochemistry of the lower uterine segment in women having previous caesarean section. This is a trial to understand the pathogenesis of placenta accreta. Clinical picture, diagnosis and management of this disorder is not the domain of this research.

\subsection{Materials and methods}

This study was performed at Early Cancer Detection Unit (ECDU) in Ain Shams Maternity Hospital .It is a controlled clinical and histopathological study. It included emergency CS hysterectomy specimens:

- $\quad 41$ C.S hysterectomies performed for P.P.A.

- 5 C.S hysterectomies performed for P.P without accreta

- 15 C.S were performed for other obstetric complications served as control. It included obstetric hysterectomy specimens performed for other causes rather than placenta accreta for example post partum hemorrhage and rupture uterus.

- Nineteen (19) cases were archeival before 2012 and twenty seven (27) new cases till January 2014.

- The available history and clinical data were collected after an electronic data base search including review of all patient's history, maternal age, parity, gestational age at time of delivery, previous caesareans section delivery and previous uterine curettage for pregnancy terminations or evacuations associated with trauma or infection compared with the final pathologic or operative findings or with both .

- All specimens were prepared and stained for Haematoxylin and Eosin (H.E), Masson trichrome stain (for collagen and smooth muscle), Orcein (for elastic fibers) and immunohistochemistry (IHC) stain for Vascular Endothelial Growth Factor Receptor (VEGFR).

Tissue staining techniques and Immunohistochemistry

Tissue prepatation:

All tissues were fixed in $10 \%$ neutral buffered formalin solution to import firm consistency for a period of 48 hours to 1 week. The tissues were prepared for sectioning by using paraffin wax embedding method. After trimming paraffin wax blocks were cut into $5 \mu$ thickness sections, by rotary microtome. Sections were transferred to water-bath to remove wrinkles. Sections were fixed on slides smeared with drop of Mayer's egg albumin. Then slides were stained with Haematoxylin and Eosin, Masson's trichrome and Orcein.

Haematoxylin and Eosin (H\&E):

Paraffin-embedded tissue sections were deparaffinized and hydrated using xylene and graded ethanol followed by distilled water. The slides were placed in Harris hematoxylin (stock solution of 5 $\mathrm{g}$ hematoxylin , $50 \mathrm{~mL} 100 \%$ alcohol, $100 \mathrm{~g}$ potassium alum $1 \mathrm{~L}$ distilled water, $2.5 \mathrm{~g}$ mercuric oxide, and $40 \mathrm{~mL}$ glacial acetic acid) for 10 minutes and washed in running tap water and lithium carbonate for blueing. The slide was then counterstained in $1 \%$ eosin solution for 4 minutes and then washed in running tap water followed by graded ethanol and xylene prior to mounting.

Masson trichrome stain for collagen:

Paraffin-embedded tissue sections (4 micron thick) were stained with Masson stain for collagen as follows: The tissue was deparaffinized and hydrated using graded ethanol and xylene solutions followed by distilled water. The tissue slides were placed in Weigert iron haematoxylin stain followed by counterstaining with Biebrich scarlet-acid fuchsin and aniline blue. Trichrome best demonstrates the relations of muscle cells to collagen.

Orcein has been used to demonstrate elastic fibers:

Paraffin-embedded tissue sections (4 micron thick) were stained with Orcein stain for elastic fibers as the following: Before staining tissue sections was oxidized in $0-3 \%$ potassium permanganate solution and decolorized in $1-5 \%$ oxalic acid. They were then stained for four hours into a solution of $4 \mathrm{~g}$ Orcein (Merck) dissolved in $100 \mathrm{~mL} \mathrm{70 \%} \mathrm{ethanol,} \mathrm{adjusted} \mathrm{to} \mathrm{pH} 2$ with $\mathrm{HCL}$.

Immunohistochemistry for VEGFR:

Immunohistochemistry for VEGFR was performed on serially cut 5 micron sections of formalin fixed paraffin-embedded specimens. Following heat-mediated antigen retrieval (citrate buffer, $\mathrm{pH}$ 6.0), sections were peroxidase blocked and then incubated for one hour with $2 \%$ normal donkey serum to block non specific staining. The following primary antibodies and dilutions were used: Monoclonal mouth antihuman VEGFR (VG-1, 1:100, AbcamInc, Cambridge, MA). Incubation with primary antibodies was done over night at $4^{\circ} \mathrm{C}$. Detection was performed with biotinylated goat anti mouth IgG (1:600 , Jackson Immuno Research Laboratories , Inc. , West Grove, PA )followed by Avidin-Biotin staining (Vectastain Elite $\mathrm{ABC}$; Vector Laboratories , Burlingame , CA) ;Vector Nova Red( Vector laboratories) as chromogen , and hematoxylinas counter stain . Slides where the first antibody was omitted served as negative controls.

All slides were examined under light microscope and photographic documentation of important findings was done.

Statistical Methods:

Statistical analysis was performed using Microsoft Excel version 2010 and Statistical Package for Social Sciences (SPSS) for Windows version 15.0. Data were described as range, mean and standard deviation (for numeric parametric variables), using also the mean, standard error, student t-test and Chi square tests.

Ethical consideratins :

The study protocol was approved by the Ethics Research Committee of Ain Shams University, Faculty of Medicine, Department of Obstetrics and Gynecology.

\section{Results}

The mean age for the cases was (33.4) while that of the control was 30 years. The difference is statistically significant to be $(\mathrm{p}<0.004)$. The parity was more among cases $(\mathrm{p}<0.001)$ as discussed in table (1).

History of previous C.S. was much more among cases. Thus was highly significant $(\mathrm{p}<0.001)$. The mean gestational age was less among cases (35.78) weeks compared to (38.152). This was statistically significant $(\mathrm{p}<0.004)$ (table 1$)$

The majority of cases has chorionic villi infiltrating the myometrium (89.3) compared to non among thecontrol gap. Difference was highly significant $(\mathrm{p}<0.001)$ (table4).

Among cases placenta accreta vera existed in $28.2 \%$, increta in $54.35 \%$ and percreta in $6.52 \%$. Table: 5 , fig (1).

Histology and histopathology:

Fibrosis and collagen fibers as stained my M.T. and distortion of muscle fibers and collagen was much prevalent among cases compared to control. Differences are highly significant $(\mathrm{p}<0.001)$ (table:6) (fig:5a,5b,6a,6b,7b,9a,9b,11,12a, 12b,13b,16b,17a,17b).

Haemorrhage in the myometrium was evident among cases compared to control (Fig 10, 11, 12) (Table 6).

The degree of elastic fibers as stained by orcein is discusses in (table 3) (Fig 5c, 7c, 8c). Difference is highly significant $(\mathrm{p}<0.001)$.

\section{Discussion}

Caesarean section is a major obstetric operation. Caesarean section rates are increasing in many middle and high-income countries with the justifications that higher rates of C-section are associated with better outcomes "as solved by (Belizan et al., 1999)[20]". In the USA it increased from 21.2 to $32.8 \%$ from 1990 to 2011 "as solved by (Van der Voet et al., 2014)[21]. The rate of caesarean delivery has been increasing in lower-resource countries, coinciding with increasing hospital delivery rates - as advocated by the Safe Motherhood Initiative to reduce maternal mortality "as solved by (Stanton et al. , 2006)[22]" . At Ain Shams University Hospital, the incidence of C.S increased from $20 \%$ in 
1993 to $44 \%$ in 2013and expected to be more (Ain Shams Maternity Hospital Statistics). As the number of previous CDs rose, the prescence of placenta previa increased the likelihood of placenta accreta from $3.3-4 \%$ in women who underwent their first CD to $50-67 \%$ in women with $4 \mathrm{CDs}$ "as solved by (Nicole et al, .2011)[23]" WU et al. , 2005 reported the incidence of placenta accreta in a cohort study to be high, 1:533 for the period 19822002, much greater than previous reports ranging from 1:4027 in the 1970 s to $1: 2510$ in the 1980 s . In the current study almost $50 \%$ of our cases were in 2012 and 2013 and the rest of cases from 2006 till 2010. This might be explained by a rising CD incidence. In the current study 46 caesarean hysterectomy, $98 \%$ of the cases had at least one previous C.S. The association of placenta previa and placenta accreta is well recognized. Eleven cases of the study group had placenta previa, 54.4\% of cases had placenta previa centralis which is another risk of placenta accreta. In "Armstrong et al., (2004)[24]" found that the median maternal age is around 34 years and the median parity was 2.5 . It is found that the mean maternal age is 33 range (from 21 to 46 years) and the median parity is 3 with IQR 2.2 which was highly significant P-value $<0.001$. So the advanced maternal age, multiparity are risk factors as "Sivan et al., (2010)[25]" reported .Fergal, (2002) reported that the risk factors for placenta accreta are previous uterine surgery, previous D\&C. In the current study dilatation and curettage were more in cases of placenta accreta $(\mathrm{P}$-value $<0.05)$. In the current study it is found that 25 cases $(54.4 \%)$ are characterized by absence of decidua basalis which is statistically significant. In the current study it was observed that a case who had IV CS had placenta previa without adherent placenta. This could be due to the intact decidua and the muscle fibers parallel to the endometrial surface Fig: $7 \mathrm{a}, 7 \mathrm{~b}$. This proves that good healing is a protective mechanism against PA. There has been very little recently published material on the histopathology of scarring in myometrium although there are a few studies exploring the biochemistry and biomechanics of human uterine scars "as solved by (Buhimschi et al., 2005 and 2006)[26] . Most authors believe that healing in the isthmus after caesarean section occurs by scarring, but there is great variation in size and residual myometrial thickness "as solved by (Spong et al., 2011 and Vikhareva et al. ,2011)[27]" . The exact pathogenesis of placenta previa is unkown. Possible hypotheses include (1) a mechanical factor, i.e. primary deficiency of the decidua caused by local trauma to the uterine wall. (2) a biological factor i.e. abnormal maternal response to trophoblast invasion (3) a combination of both processes "as solved by (Esh Broder et al., 2011)[28]" .B In the current study the swirling patternof myofiber disarray (MD) is best identified with the Masson trichrome stain, although the vertical pattern is more easily identified with routine H\&E Fig: 8b, 9b, 12b, 13b, 16b, 17b .Myofiber disarray has more fibrous tissue. It is believed that muscle disarray with cell hypertrophy, vertical myofibers and elastosis may all be compensatory mechanisms that help to preserve the integrity of the scarred area, but that in some individuals they may be insufficient to maintain integrity of isthmic scars. In this study almost all cases show scarring (fibrosis) or distorted increased collagen. Scaring or collagen seen by Masson Trichrome (MT) with different degrees of mild, moderate and severe fibrosis. This is statistically significant. While in normal cases (control group) smooth muscle fibers are arranged parallel to endometrium lining, faint and little stain of interstitial collagen by MT (blue) Fig: (5b, 6b). Elastosis is a focal accumulation of excessive amounts of elastic fibers "as solved by (Uitto, 2008)[29]". Elastosis occurs in other tissues as the lung, gut and the heart have been shown to be a response to injury. It is well known that globular elastosis is a manifestation of significant pathology where scars form in rhythmically moving tissue "as solved by (Yousem, 2001)[30]". We interpret that the abundant elastic fibers noted in our specimens with Orcein stain are indicative of abnormal wound healing in response to previous CS or D\&C. Fig: (8c, 15a, 17c). It is assumed that the most important reason for placenta accreta is implantation of the placenta in areas with poor blood supply.

Immunohistochemical VEGFR is found in the interstitial extra villous trophoblasts (iEVTs) penetrating beneath the basal plate in accreta, increta and percreta cases Fig: (11, 12a, 13a, 13b, 15a). These findings are suggestive of a striking similarity among accreta extra villous trophoblasts (EVTs) and cancer cells. Previous in vitro data generated in a cultured trophoblast cell system are in support of these finding. "as solved by (Wehrum et al., 2011)[31]" .It was found that there was abundant increased extracellular VEGFR staining in cases of placenta accreta which hint that VEGFR may play an active functional role. In point, our findings of epithelial-to-mesenchymal transition (EMT) in accreta may be a functional consequence of VEGFR stimulation of EVT motility at the local level. A study by "Tseng et al., (2006)[32]" has previously noted increased VEGFR expression in a cohort of patients with placenta accreta. The sonographic appearance of intraplacental sonolucent spaces (lakes or lacunae) is a frequent finding in cases of suspected placenta accreta "as solved by (Yang et al., 2006)[33]". The pathophysiology behind the occurrence of placental lacunae is unknown, but their presence suggests an aberrant vascular remodeling pattern "as solved by (Comstock et al., 2004)[34]". It was observed that there was prominent VEGFR staining in the vascular lacunae of the patients with previa accreta Fig: (7e, 8d, 13c, 17d). A similar finding was not encountered in the placental biopsy specimens of normally invaded basal plate's .Fig: (6d).

In normal placentation, extravillous trophoblast invades the decidua controlled and converts the spiral arterioles of the endometrium to uteroplacental vessels.

Decidual tissue apparently limits placental growth. In placenta accreta normal decidua fails to form, most times locally because the subjacent endometrium is deficient and cannot decidualize. The trophoblast invades and penetrates into the myometrium.

It is thus possible to formulate that the possible pathogenesis of placenta accreta is almost due to previous uterine trauma (mostly CS) which leads to either scaring or poor decidua. Scarring leads to hypoxia and EVT proliferation leading to increase VEGF and proteases leading to angiogenesis and degradation of exteracellular matrix respectively leading to trophoplastic invasion. Poor decidua or absent decidua leads to decrease tissue metalloproteinases and coagulation proteases. This leads to a decrease of the protective mechanism of decidua against the expansine nature of EVT leading finally to trophoplastic invasion

\section{Recommendations}

- Correction of the etiological causes of placenta accreta.

- Confirmation of the theory that the morbidly adherent placenta is the result of the myometrial damage and the underlying collagen exposure could lead to the application of corrective measures during caesarean section, which would eliminate the predisposing factor and prevent recurrent damaged myometrium.

- This gives the attention to good caesarean section repair.

- Therapeutic application of the diagnostic advances.

- Counseling of women undergoing CD about the risks of abnormal placentation.

- Education regarding the normal labor course and the implications of first caesarean may allow women and their providers to avoid practices that increase the potential for unneeded first caesarean deliveries.

Paid by a Grant, mention the Grant name and number here. 
Table 1: Demographic and Obstetric Data in Cases and Controls

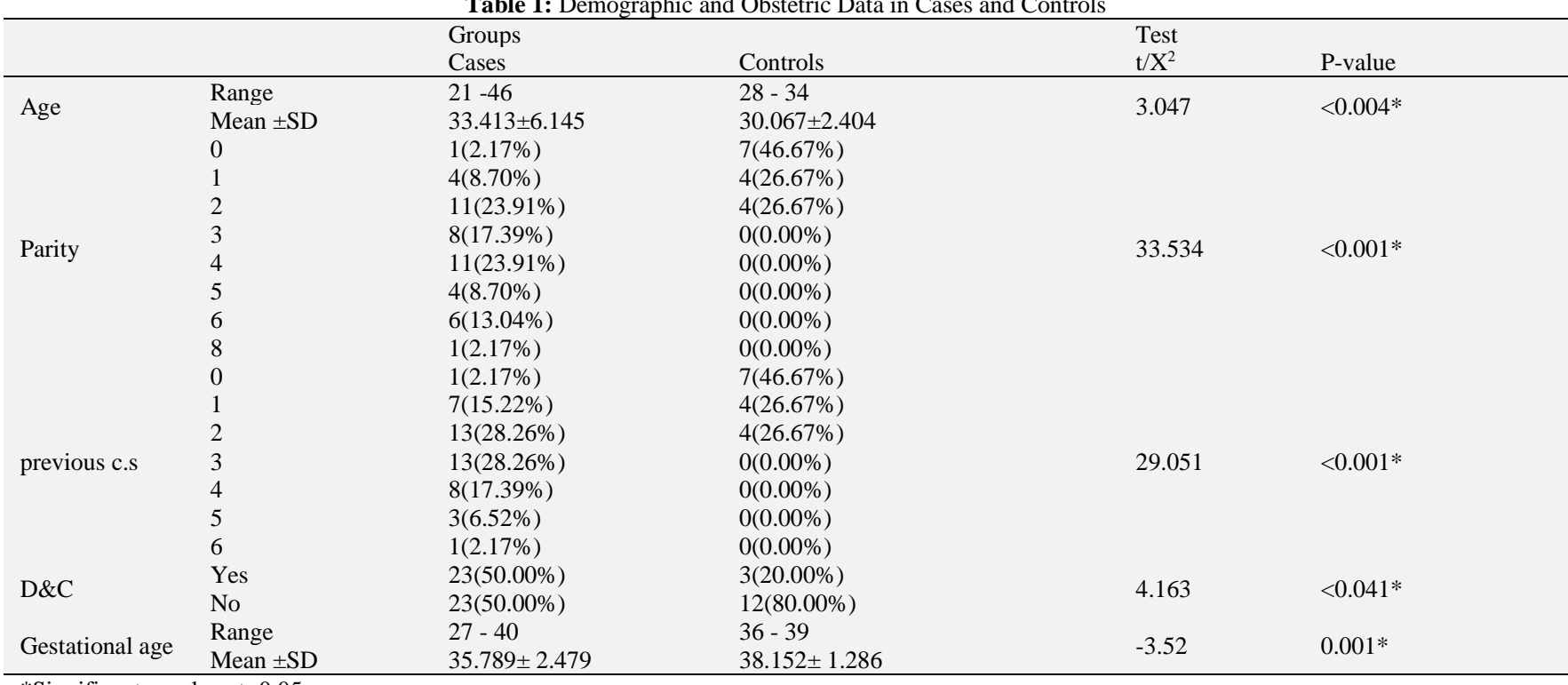

*Significant p-value at $<0.05$.

Table 2: Percent of Cases Diagnosed by Ultrasound and Placental Setting

\begin{tabular}{|c|c|c|c|c|c|}
\hline & & \multicolumn{2}{|l|}{ Groups } & \multicolumn{2}{|c|}{ Chi-Square } \\
\hline & & Cases & Controls & $\mathrm{X}^{2}$ & P-value \\
\hline \multirow{2}{*}{ Ultrasound } & Dignosed & $33(71.74 \%)$ & $15(100.00 \%)$ & \multirow{2}{*}{8.426} & \multirow{2}{*}{$0.004 *$} \\
\hline & Not dignosed & $13(28.26 \%)$ & $0(0.00 \%)$ & & \\
\hline \multirow{2}{*}{ placenta previa centralis } & Yes & $25(54.35 \%)$ & $0(0.00 \%)$ & \multirow{2}{*}{13.813} & \multirow{2}{*}{$<0.001 *$} \\
\hline & No & $21(45.65 \%)$ & $15(100.00 \%)$ & & \\
\hline
\end{tabular}

Table 3: Infiltration of the Myometrium in Cases of Placenta Previa, Accreta with Absent or Presence of Decidua. Fig : (5, 7, 8, 9, 10, 14, 15, 16, 17).

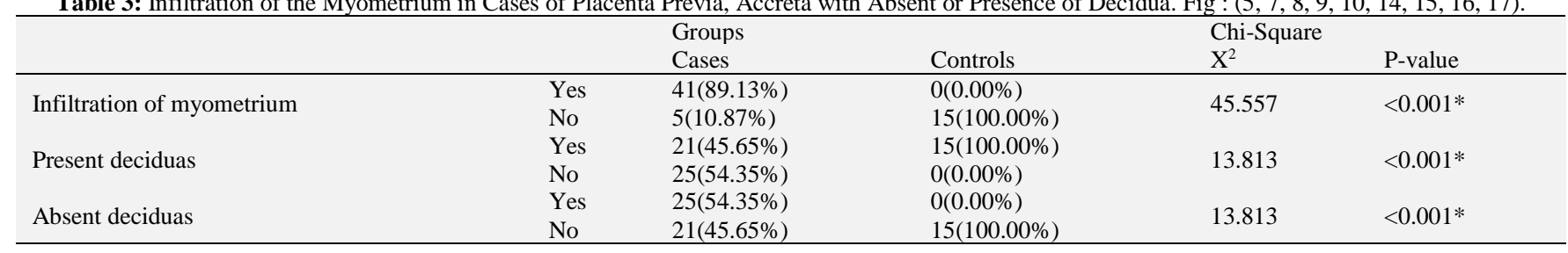

Table 4: Degree of Infiltration. Fig: $(5,15,16,17)$

\begin{tabular}{|c|c|c|c|c|}
\hline \multirow{2}{*}{ Degree of infiltration } & \multicolumn{2}{|l|}{ Groups } & \multicolumn{2}{|c|}{ Chi-Square } \\
\hline & Cases & Controls & $\mathrm{X}^{2}$ & P-value \\
\hline Normal & $0(0.00 \%)$ & $15(100.00 \%)$ & & \\
\hline No Previa & $5(10.87 \%)$ & $0(0.00 \%)$ & & \\
\hline Accreta & $13(28.26 \%)$ & $0(0.00 \%)$ & 68.05 & $<0.001 *$ \\
\hline Increta & $25(54.35 \%)$ & $0(0.00 \%)$ & & \\
\hline Percreta & $3(6.52 \%)$ & $0(0.00 \%)$ & & \\
\hline
\end{tabular}

Table 5: Degree of Fibrosis in Cases Stained Collagen Fibers by MT and Arrangement of Collagen and Muscle Fibrous. Fig: (5a, 5b, 6a, 6b, 7b, 9a, 9b, $11,12 \mathrm{a}, 12 \mathrm{~b}, 13 \mathrm{~b}, 16 \mathrm{~b}, 17 \mathrm{a}, 17 \mathrm{~b})$

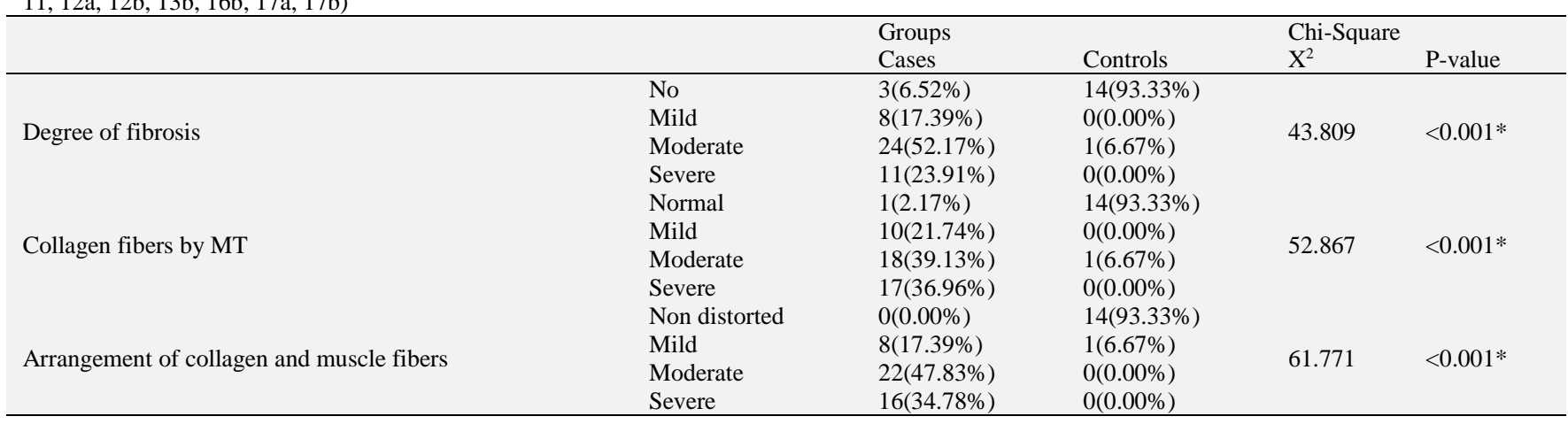

Table 6: Degree of Hemorrhage.Fig: $(10,11,12,17)$

\begin{tabular}{|c|c|c|c|c|}
\hline \multirow{2}{*}{ Hemorrhage in myometrium } & \multicolumn{2}{|l|}{ Groups } & \multicolumn{2}{|c|}{ Chi-Square } \\
\hline & Cases & Controls & $\mathrm{X}^{2}$ & P-value \\
\hline No & $3(6.52 \%)$ & $14(93.33 \%)$ & \multirow{4}{*}{44.858} & \multirow{4}{*}{$<0.001 *$} \\
\hline Mild & $16(34.78 \%)$ & $0(0.00 \%)$ & & \\
\hline Moderate & $14(30.43 \%)$ & $1(6.67 \%)$ & & \\
\hline Severe & $13(28.26 \%)$ & $0(0.00 \%)$ & & \\
\hline
\end{tabular}


Table 7: Degree of Stained Elastic Fiber by Orceinfig (5c, 7c , 8c, 15a, 17c)

\begin{tabular}{|c|c|c|c|c|c|}
\hline Smooth muscle , Blood vessel, elastic tissue by orcein & $\begin{array}{l}\text { Groups } \\
\text { Cases }\end{array}$ & Controls & $\begin{array}{l}\text { Chi-Square } \\
X^{2}\end{array}$ & & P-value \\
\hline Non distorted & & $0(0.00 \%)$ & $14(93.33 \%)$ & \multirow{4}{*}{61.771} & \multirow{4}{*}{$<0.001^{*}$} \\
\hline Mild & & $8(17.39 \%)$ & $1(6.67 \%)$ & & \\
\hline Moderate & & $22(47.83 \%)$ & $0(0.00 \%)$ & & \\
\hline Severe & & $16(34.78 \%)$ & $0(0.00 \%)$ & & \\
\hline
\end{tabular}

\section{Vegfr}

VEGFR staining was faint staining in normal cases perivillous, intravillious, extracellular. Abundant stain in cases of placenta increta. Extensive stain in cases of placenta percreta. Fig: 6d, 7e, $8 \mathrm{~d}, 13 \mathrm{c}$

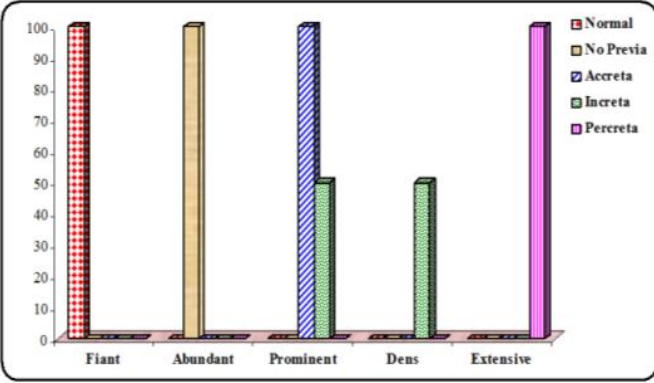

Fig. 2: VEGFR Immunohistochemical Stain.

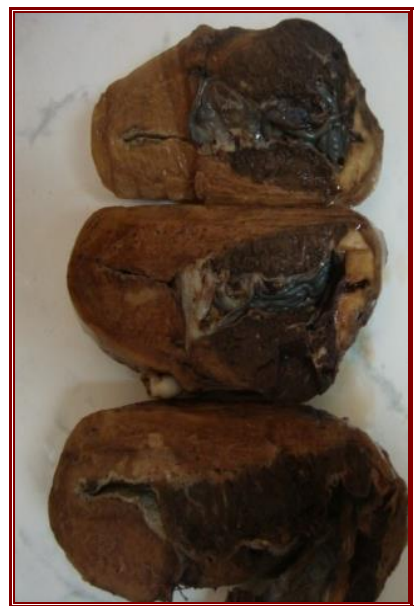

Fig. 3: Placenta Percreta Cross Section of the Uterus Placenta Invading Throughthe Myometrium.

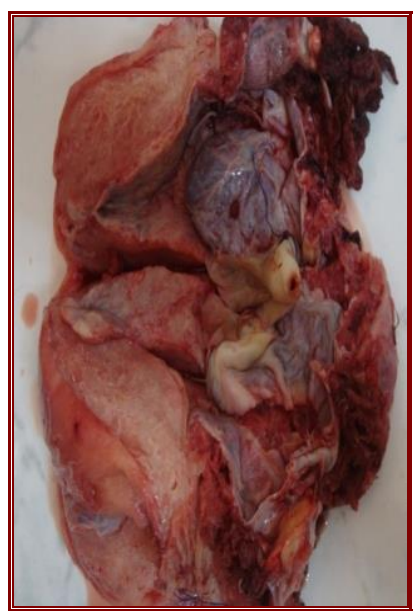

Fig. 4: Caesarean Hysterectomy Showing Placental Tissue Implanted at the Lower Uterine Segment (LUS) with Infiltration of the Myometrium.

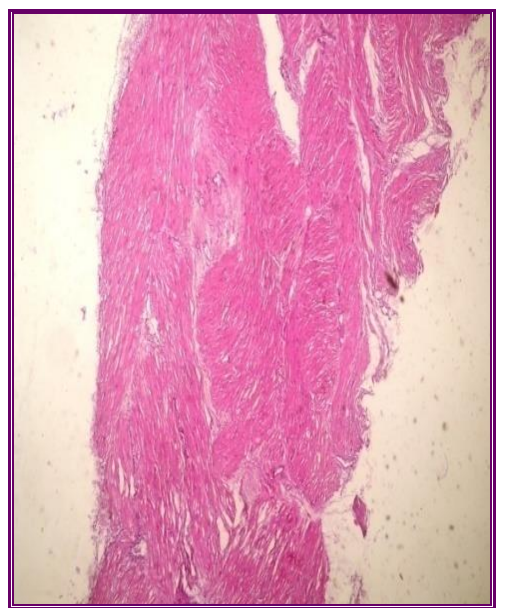

Fig. 5: a) 27 Years Primgravida H\&E X100 Slide Shows Normal Appearance of Smooth Muscle Fibers Orderly Parallel and It Is Not Hypertrophic with Little Collagen (Interstitial Fibrous Tissue)

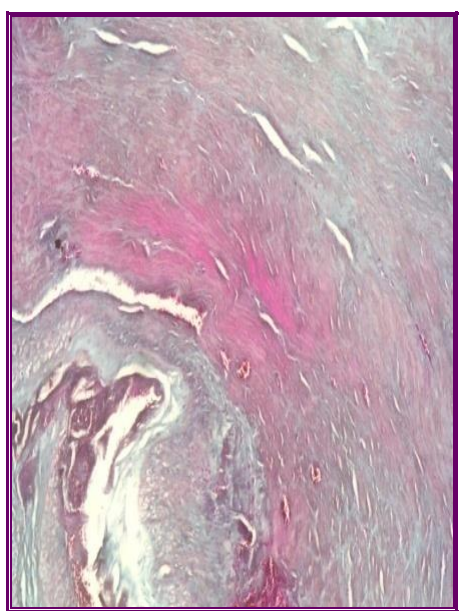

Fig. 5: B) Same Patient Masson Trichrome X100 Shows Smooth Muscle Fibers Arranged Parallel to Endometrium Lining, Faint and Little Stain of Interstitial Collagen (Blue).

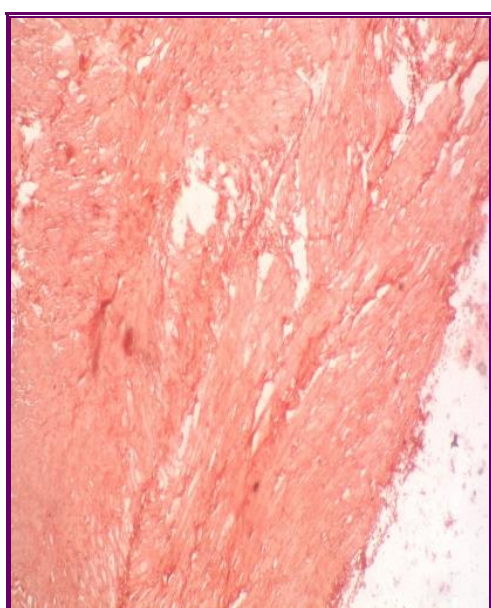

Fig. 5: C) Orcein Stain X400 Same Previous Slide Shows Normal Parallel Arrangement of Thin Elastic Fibers to the Endometrial Surface. 


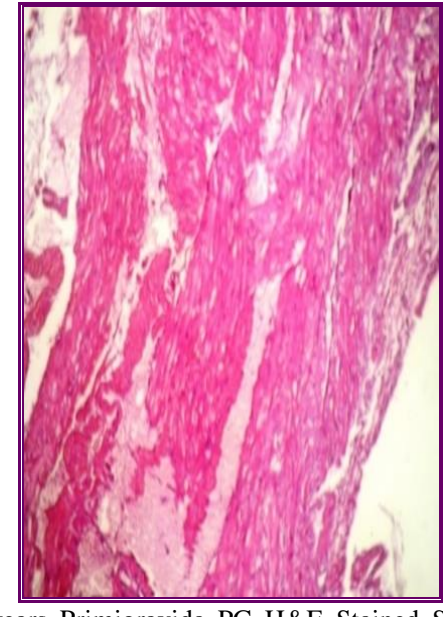

Fig. 6: A) 31 years Primigravida PG H\&E Stained Slide X100 Shows Muscle Fibers Run Parallel to Long Axis of the Endometrium Surface and Minimal Fibrous Stroma.

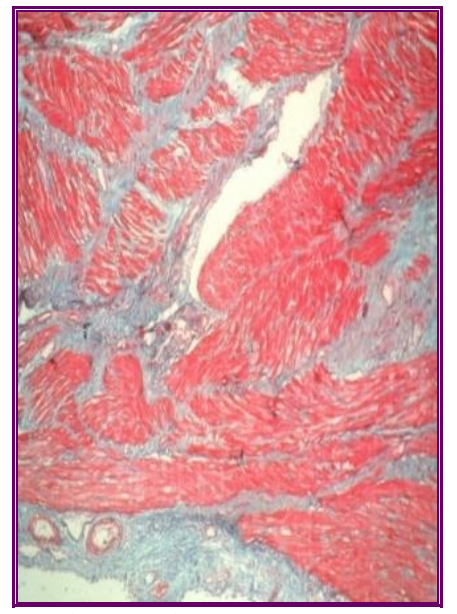

Fig. 6: B) Same Specimen Stained by Masson Trichrome X100 Shows Collagen (Blue), Muscle Fibers (Red) are Orderly Parallel and Not Hypertrophied.

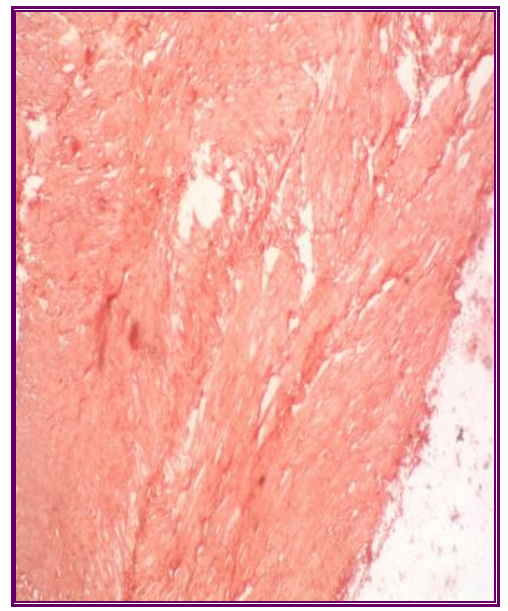

Fig. 6: C) Orcein Stain X400 Same Previous Slide Shows Normal Paralle Arrangement of Thin Elastic Fibers to the Endometrial Surface.

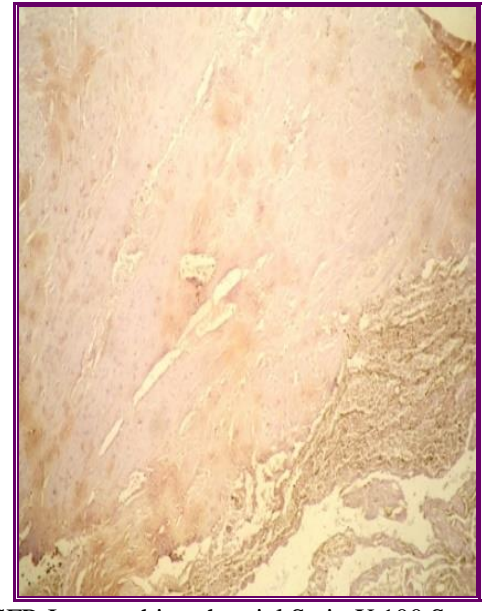

Fig. 6: D) VEGFR Immunohistochemial Stain X 100 Same Previous Specimens Shows Normal Parallel Arrangement and Faint Stain.

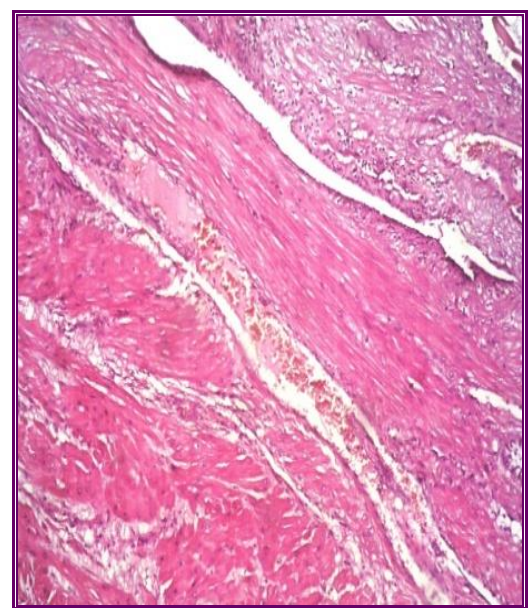

Fig. 7: A) 45 Years Previous IV CS Placenta Previa Slide Stained by H\&E X100 Shows Normal Parallel Arrangement of Smooth Muscle Fibers with Decidua Layer is Still Present.

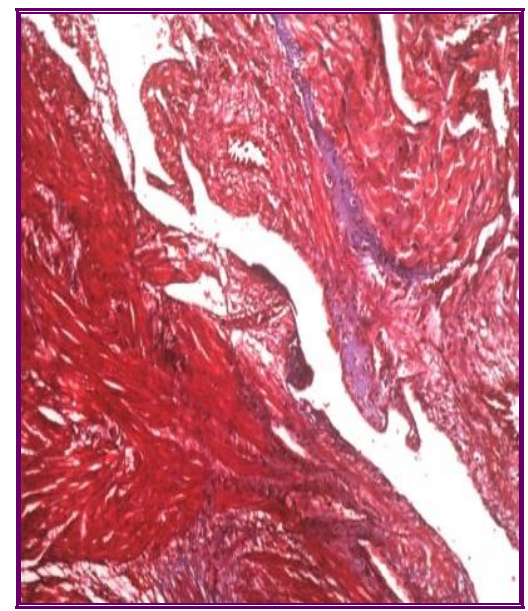

Fig. 7: B) 45 years Previous IV CS Placenta Previa Slide Stained by MT X100 Shows Normal Parallel Arrangement of Smooth Muscle Fibers (Red) and Little Amount Extracellular Matrix and Collagen (Blue). 


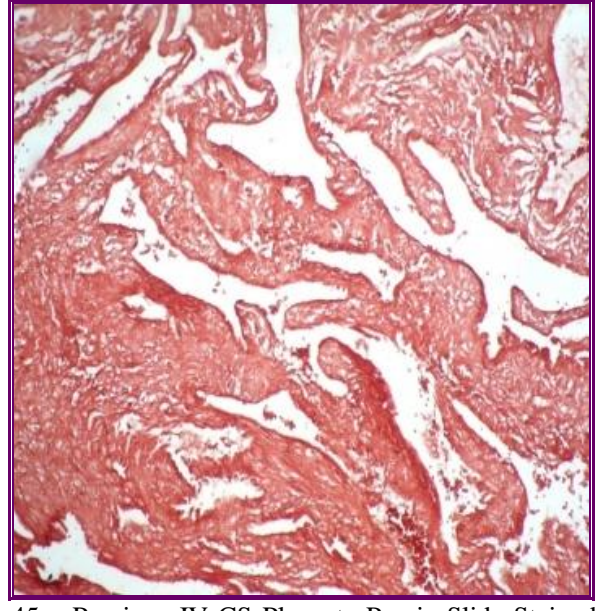

Fig. 7: C) 45 y Previous IV CS Placenta Previa Slide Stained by Orcein X400 Shows Marked Increase of Vascularity with Thin Elastic Fibers in the Wall of Blood Vessels.

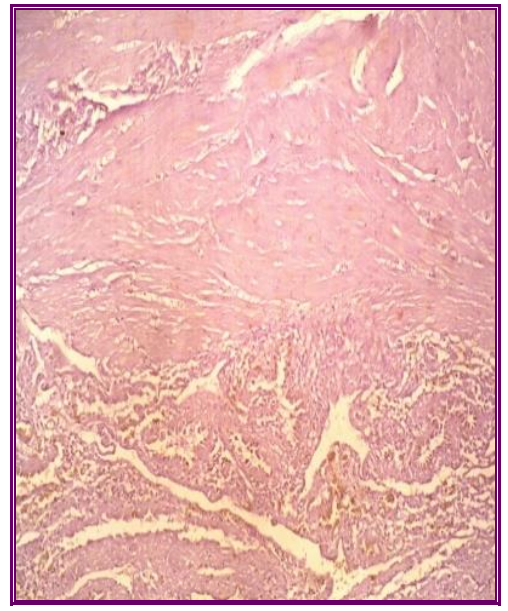

Fig. 7: E) Same Specimen with VEGFR Immunoreactivity X400 in Placental Bed Biopsy Shows Prominent Vasculature of Smooth Muscle and Interstitial Abundant Stain, Abundant Extracellular Stain.

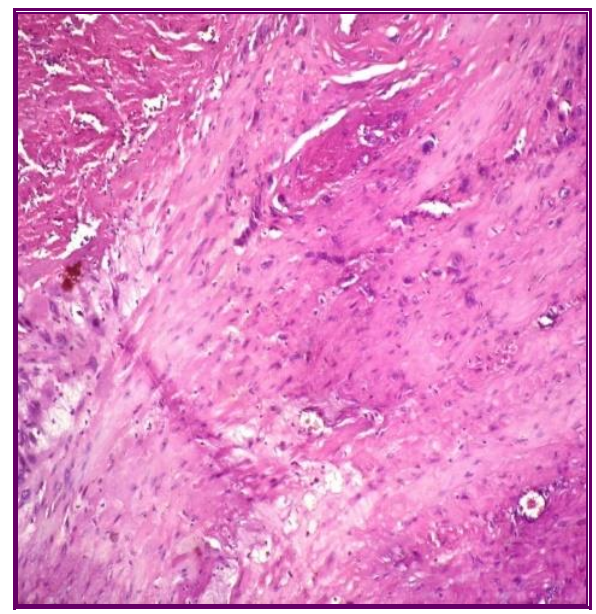

Fig. 8 A) 37 Years P5+1 Last II CS A Case of Placenta Accreta (H\&E) X400 Shows Trophoplastc Infiltration of the Myometrium.

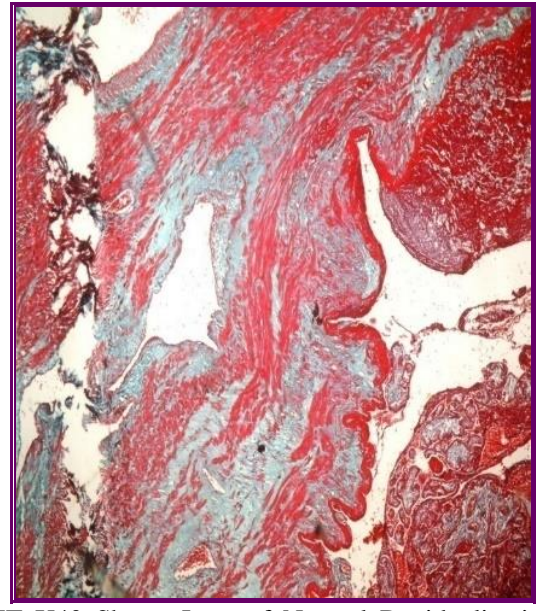

Fig. 8 B) MT X40 Shows Loss of Normal Decidualization, Prominen Myofibers Disarray with Degenerative Changes and Increased Extracellular Collagen (Blue Colour).

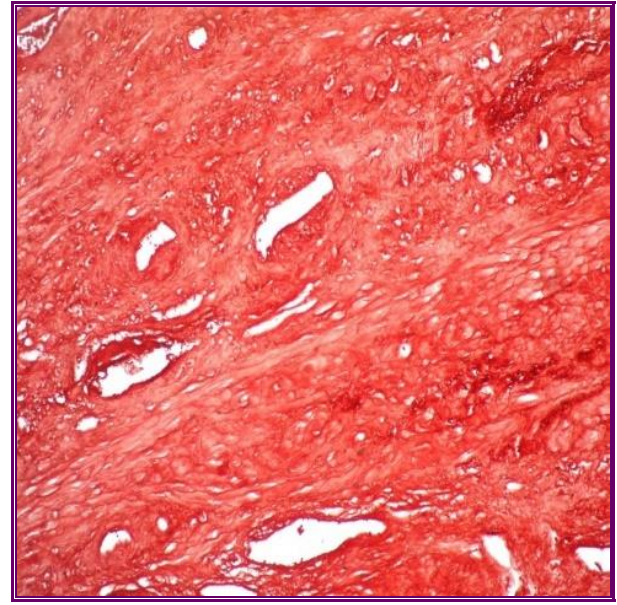

Fig. 8: C) Orcein Stain X400 Same Patient Shows Marked Increase of Vascularity with Prominent Elastosis (Thick Elastic Fibers).

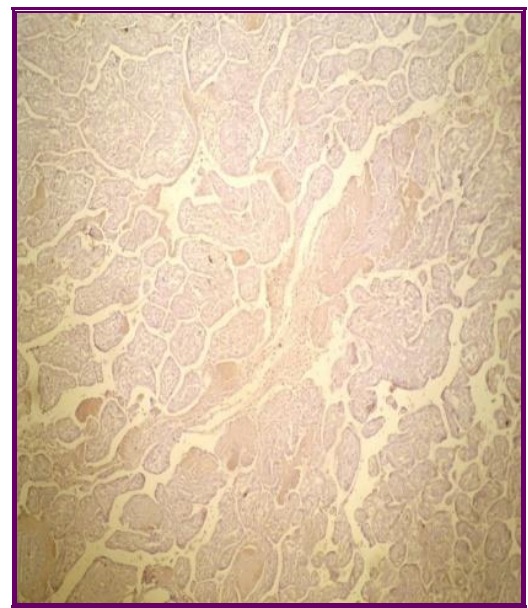

Fig. 8: D) Same Specimen with VEGFR Immunoreactivity X100 Cesarean Hysterectomy Biopsy Shows Positive Perivillous Stain and Abundant Extracellular Matrix (Brown). 


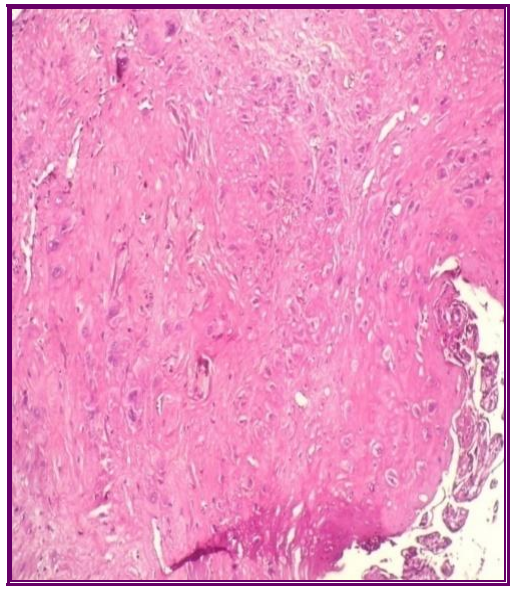

Fig. 9: A) A Case Number 361-2010 P6 Previous II CS Placenta Accreta H\&E X400 Shows Prominent Myofibers Disarray. Abundant Interstitial Collagen. Loss of Decidual Lining and Its Replacement by Loose Connective Tissue.

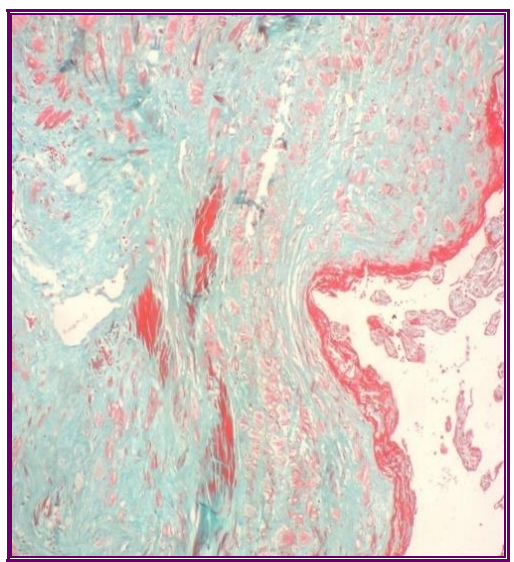

Fig. 9: B) Same Specimen Masson Trichrome X100 Shows Marked Degenerative Changes in Smooth Muscle Fibers with Myofibers Disarray, Excessive Interstitial Collagen Stained (Blue).

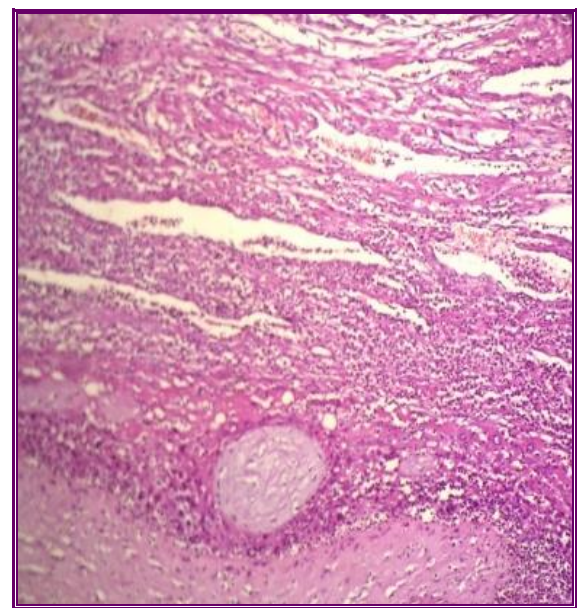

Fig. 10: 37years Previous II CS A Case of Placenta Accreta Very Superficial Infiltration Stained by (H\&E) X100 Shows Marked Increase of Vascularity and Infiltration of the Myometrium by Placental Tissue and Mononuclear Inflammatory Cells.

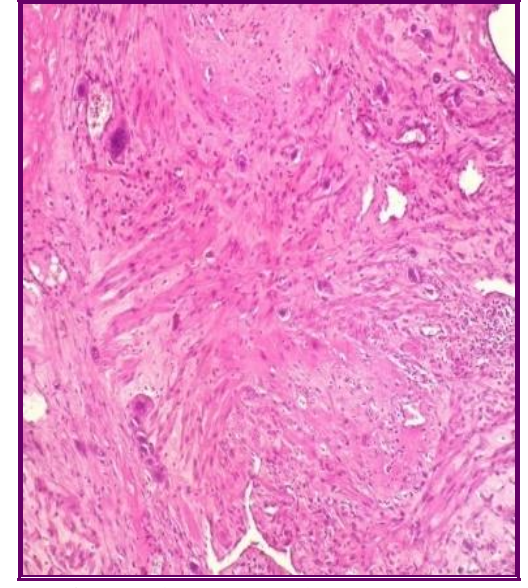

Fig. 11: 36 Years for Previous 4 CS Placenta Accreta H\&E X400 Slide Shows Hyptrophy of Smooth Muscle Fibers, Prominent Smooth Muscle Fibers Disarray in the form of Smooth Muscle Fibers Swirling in All Directions. Increased Interstitial Fibrous Tissue. Penetration of Extravilloustrophoblast (Evts) Judged by their Bright Red Cytoplasm and Large Vesicular Nuclei.

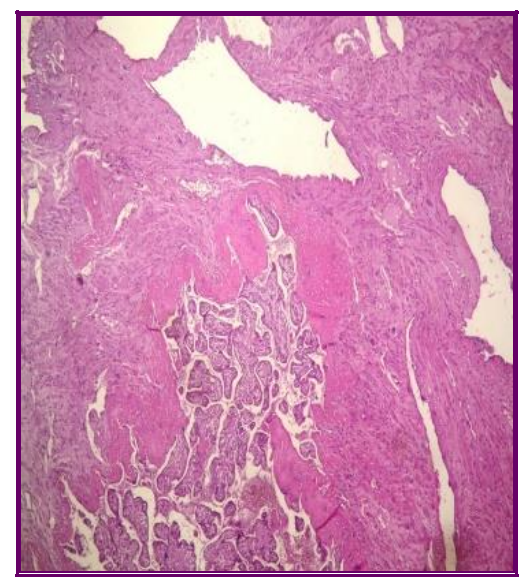

Fig. 12: A) H\&E X40 Shows Prominent Smooth Muscle Fibers Disarray (MD) Perpendicular to Endometrium with their Swirling in All Directions Increased Interstitial Fibrous Tissue (Collagen). Loss of Decidua and Its Replacement by Loose Connective Tissue. Marked Increase of Vascularity With Dilated Blood Vessels. Infiltration of Extravilloustrophoblast (EVTS), Interstitial Type.

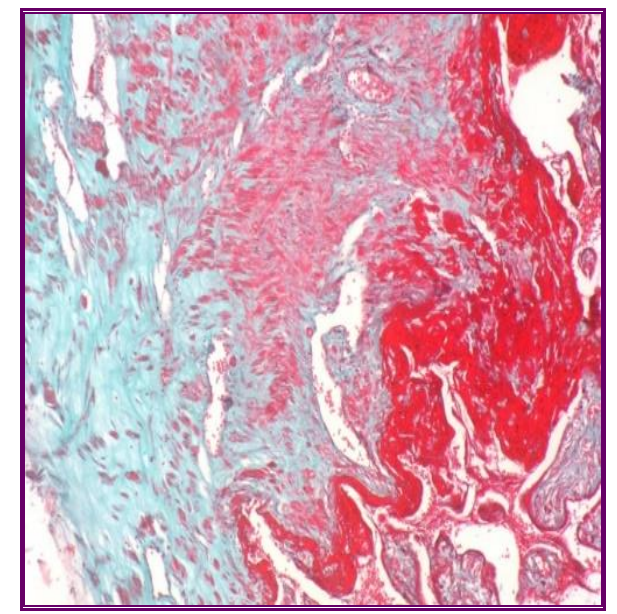

Fig. 12: B) Masson Trichrome X400 Shows Muscle Fibers are Red (Hypertrophic) Compared to Normal. Collgenous Area (Blue) More Prominent. 


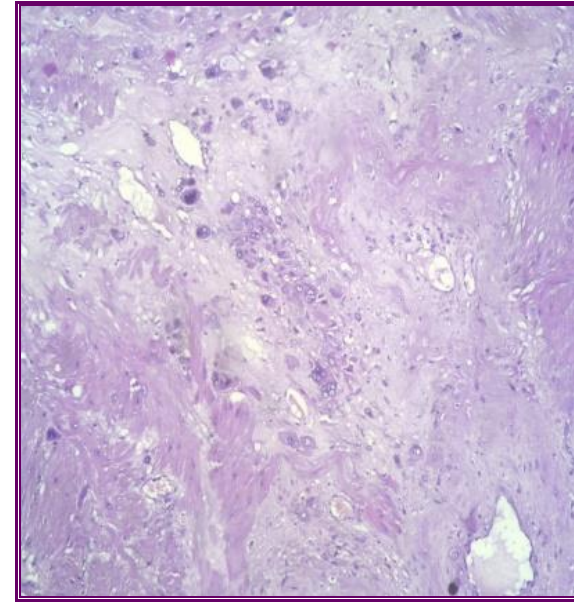

Fig. 13: A) 34 Years for Previous III CS Placenta Increta H\&E X400 Slide Shows Penetration of Extravilloustrophoblast (Evts) Judged by Their Bright Red Cytoplasm and Large Vesicular Nuclei.

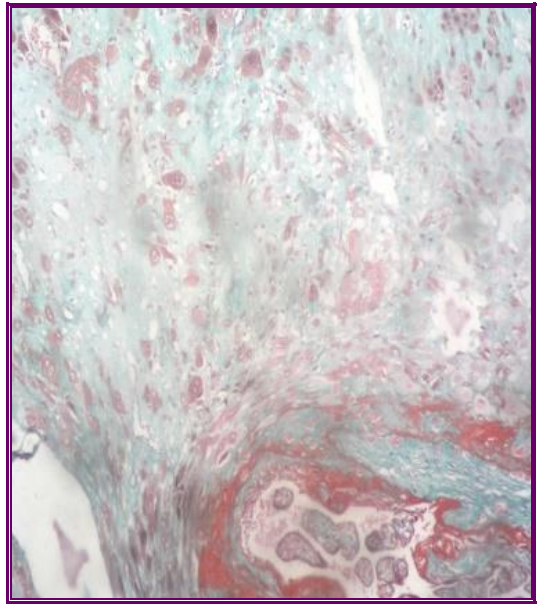

Fig. 13: B) Same Pervious Patient Slide Stained by Masson Trichrome X400 Shows Hyptrophy of Smooth Muscle Fibers, Prominent Smooth Muscle Fibers Disarray (Red),Abundant Ievt, Increased Interstitial Fibrous Tissue (Collagen Blue).

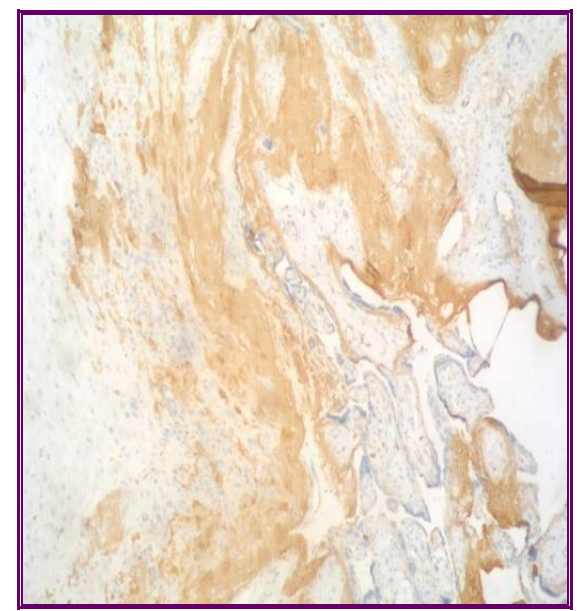

Fig. 13: C) Same Slide VEGFR Immunoreactivity Shows Perivillous Stain and Abundant Extracellular Matrix (Brown).

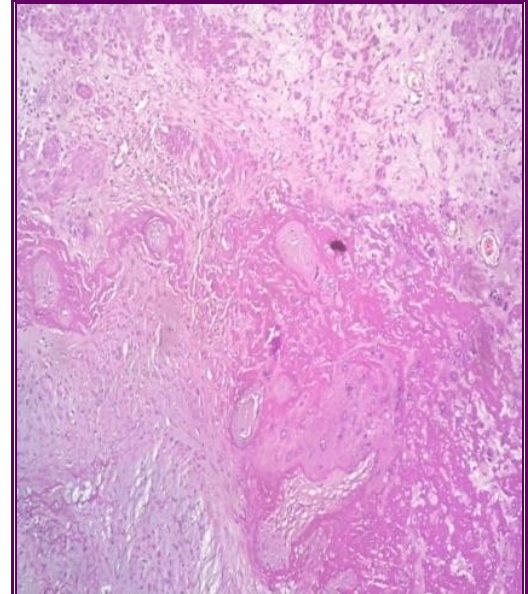

Fig. 14: 31 Years Pervious II CS Placenta Increta H\&E Stain X100 Shows Trophoblastic Invasion with Absent Decidua.

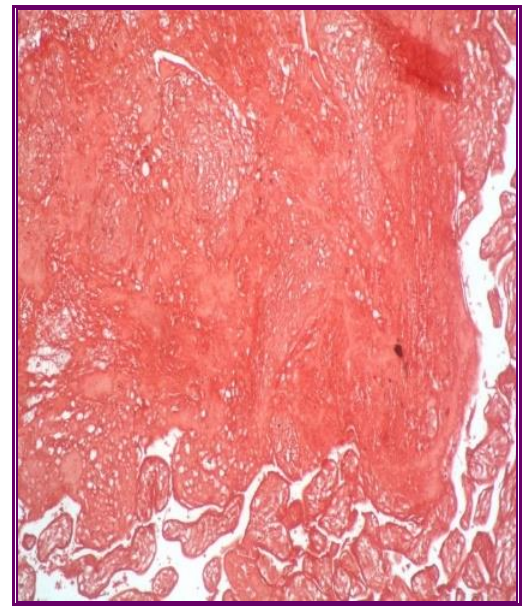

Fig. 15: a) 36 years Pervious II CS placenta incretaorcein $x 40$ show marked increased vascularity, mild to moderate elastosis, EVTs, villi invading the myometrium.

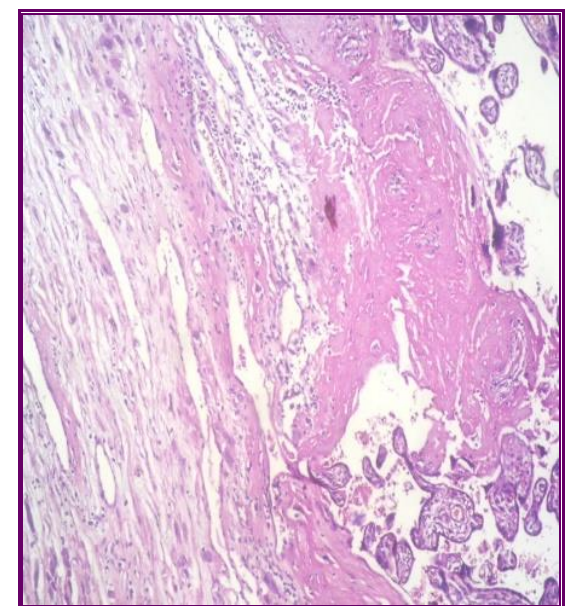

Fig. 15: B): 36 Years Pervious II CS H\&E X100 Placenta Incretashows Trophoblastic Infilteration of the Myometrium. 


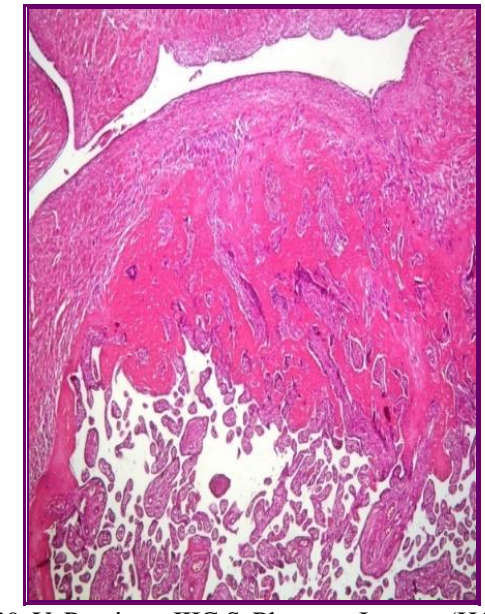

Fig. 16: A): 29 Y Previous IIIC.S Placenta Increta (H\&E) X40 Shows Invasion of the Myometrium by Placental Chorionic Villi. Prominent MD, Smooth Muscle Fibers Degenerative Changes, Increased Vascularity, Absent Decidua, with Mononeuclar Infiltration.

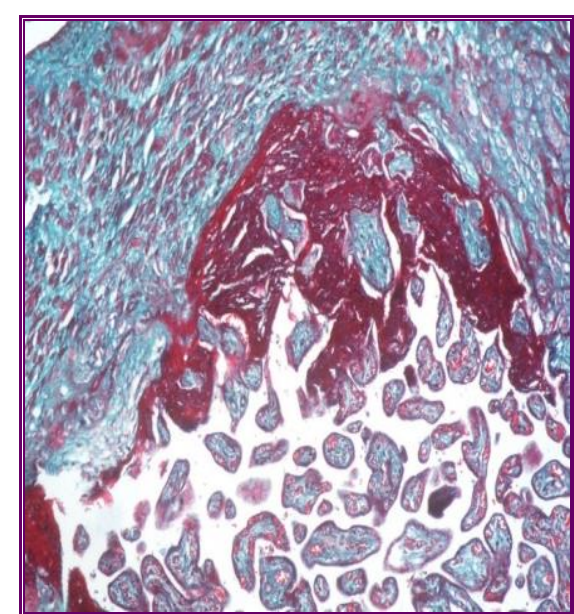

Fig. 16: B): Same Slide Masson Trichrome by Low Power X40 Shows the Villi Invading the Myometrium ,Also Shows Marked Degenerative Changes in Smooth Muscle Fibers (Red) and Prominent MD Accompanied by Abundant Deposition of Collagen (Blue).

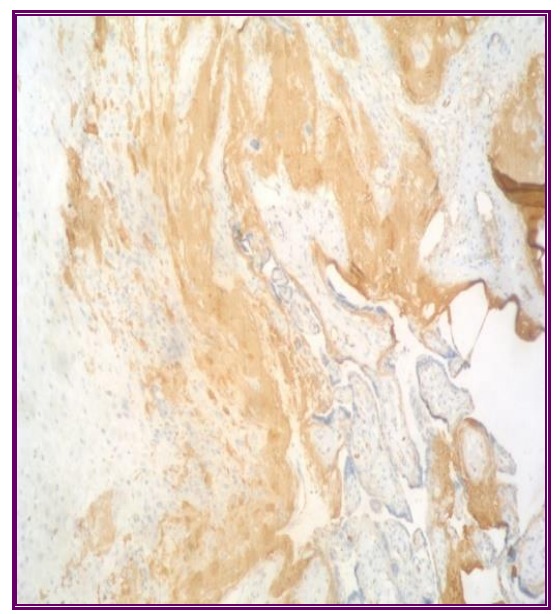

Fig. 13: C): Same Slide VEGFR Immunoreactivity Shows Perivillous Stain and Abundant Extracellular Matrix (Brown).

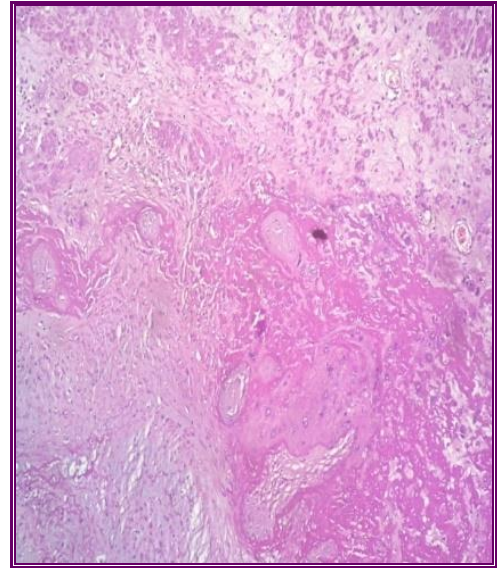

Fig. 14: 31 Years Pervious II CS Placenta Increta H \& E Stain X100 Shows Trophoblastic Invasion with Absent Decidua.

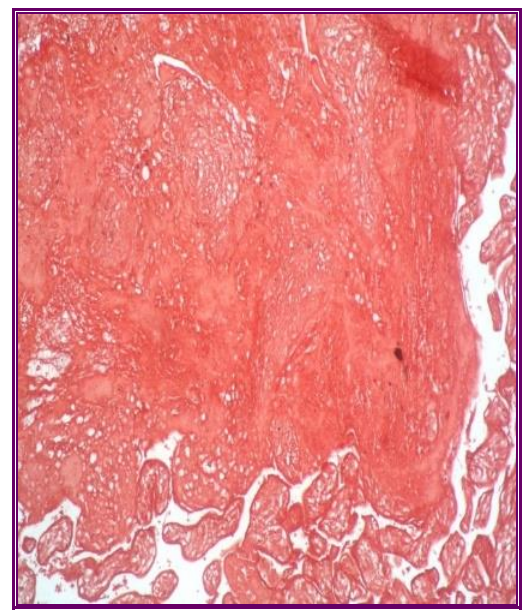

Fig. 15: A): 36 Years Pervious II CS Placenta Incretaorcein X40 Show Marked Increased Vascularity, Mild to Moderate Elastosis, Evts, Villi Invading the Myometrium.

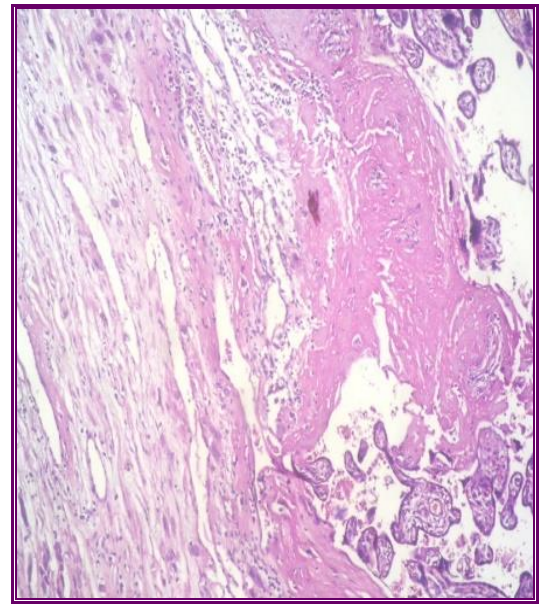

Fig. 15: B): 36 Years Pervious II CS H\&E X100 Placenta Incretashows Trophoblastic Infilteration of the Myometrium 

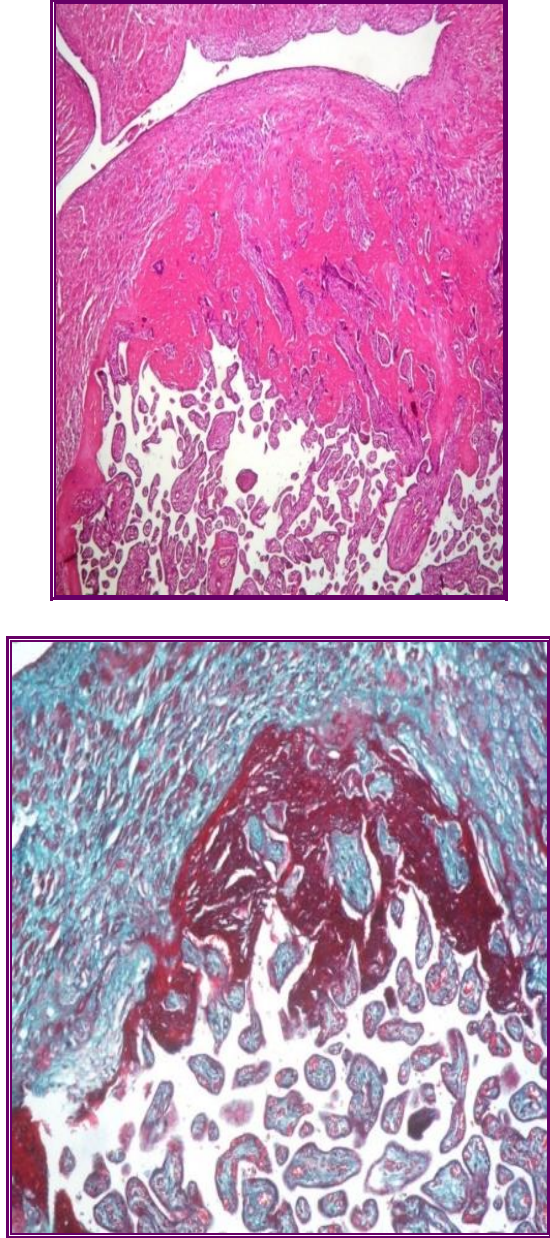

Fig. 16: B): Same Slide Masson Trichrome by Low Power X40 Shows the Villi Invading the Myometrium ,Also Shows Marked Degenerative Changes in Smooth Muscle Fibers (Red) and Prominent MD Accompanied by Abundant Deposition of Collagen (Blue).

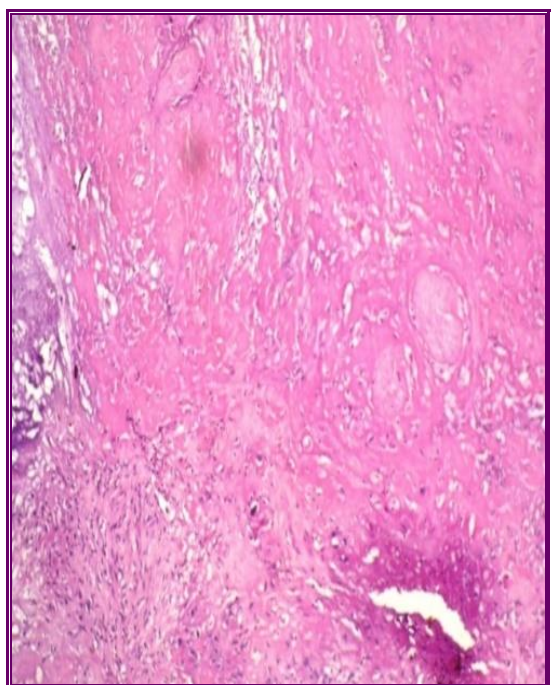

Fig. 17: A): 38y Previous III CS Placenta Percreta H\&E X400 Slide Shows Smooth Muscle Fibers Swirling In All Directions with Abundant Extracellular Matrix and Dense Inflammation with Placental Villi Invading Whole Thickness of Myometrium.

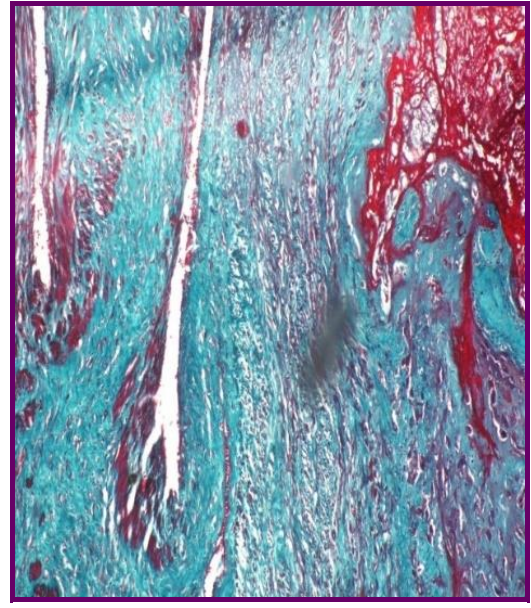

Fig. 17: B): Same Patient Masson Trichrome Stain X100 Shows Abundant Extracellular Collagen (Staid Blue) with Very Thin Muscle Fibers (Staind Red) with Prominent Myofibers Disarray.

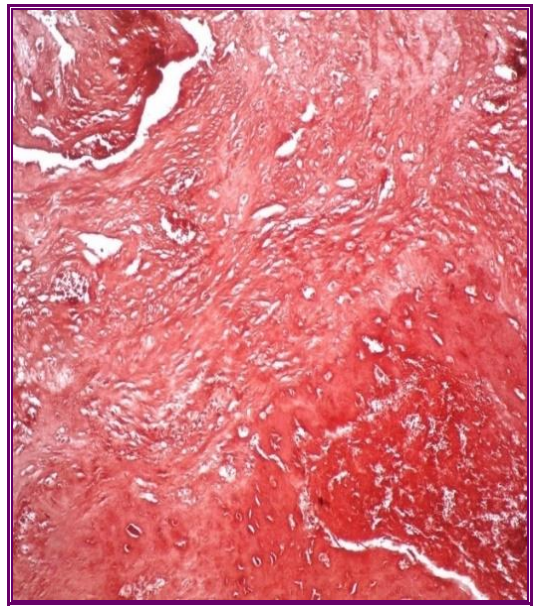

Fig. 17: C): Same Patient Orcein X100 Shows Increased Vascularity with Elastosis (Thick Elastic Fibers)

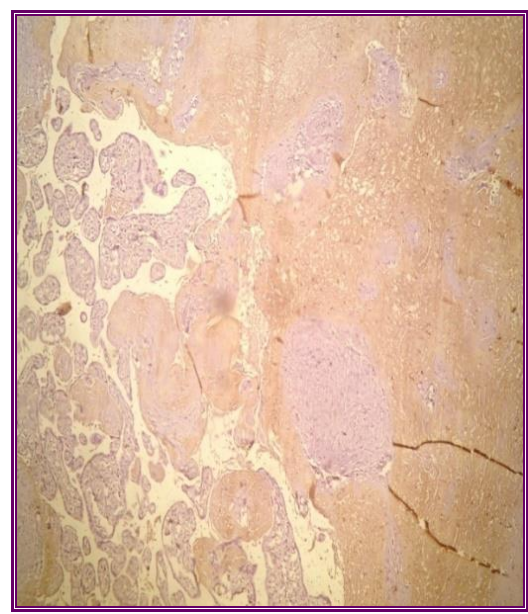

Fig. 17: D): Same Specimen with VEGFR Stain in Placental Bed Biopsy Shows Over Expression of VEGFR in Perivillousfibrinoid Tissue.

\section{References}

[1] Zelop C and Heffner LJ. The downside of caesarean delivery: short and long term complications. ClinObstetGynecol; 2004; 7.

[2] RCOG: The Sentinel National Caesarean Section Audit ReportRCOG Clinical Effectiveness Support Unit. RCOG Press; 2001.

[3] (AIHW, 2003).

[4] Hamilton BE, Martin JA and Sutton PD. Birth: Preliminary data for Natl Vital Stat Rep2003; 51:4-5. 
[5] Hamilton BE, Martin JA, Ventura SJ, Births. reliminary Data for 2009. Hyattsville, MD: National Center for Health Statistics; Report No 2010; 59: 3 .

[6] Van der Voet LF1, Vervoort AJ, Veersema S, BijdeVaate AJ, Brölmann HA and Huirne JA. Minimally invasive therapy for gynaecological symptoms related to a niche in the caesarean scar: a $\begin{array}{lll}\text { systematic } & \text { review. } & \text { BJOG. 2014; }\end{array}$ https://doi.org/10.1111/1471-0528.12537.

[7] Scott JR. Caesarean delivery on request: Where do we go from here? Obstet Gyneecol 2006; 107:1222-3. https://doi.org/10.1097/01.AOG.0000221482.51250.3c.

[8] Khong TY. The pathology of Placenta accreta -a worldwide epidemic. J ClinPathol; 2008; 61: 1243-12. https://doi.org/10.1136/jcp.2008.055202.

[9] Stanton CK and Holtz SA. Levels and trends in caesarean birth in the developing world. Stud FamPlann 2006; 37(1):41-8. https://doi.org/10.1111/j.1728-4465.2006.00082.x.

[10] Karkee et al 2014).

[11] Hamilton BE, Martin JA, Ventura SJ, Births. reliminary Data for 2009. Hyattsville, MD: National Center for Health Statistics; Report No 2010; 59: 3 .

[12] Miller DA, Chollet JA and Goodwin TM. Clinical risk factors for placenta praevia-placenta accreta. AmJ ObstetGynecol; 1997; 177: 210-214. https://doi.org/10.1016/S0002-9378(97)70463-0.

[13] Armstrong CA, Harding S, Matthews $T$ and Dickinson JE. Is placenta accreta catching up with us? Aust N Z J ObstetGynaecol. 2004; 44(3):210-3. https://doi.org/10.1111/j.1479828X.2004.00208.x.

[14] Marshall NE, Fu R and Guise JM. Impact of multiple caesarean deliveries on maternal morbidity: a systematic review. Am J Obstet Gynecology. 2011; 205: 262.e1-8. https://doi.org/10.1016/j.ajog.2011.06.035.

[15] Sivan E, Spira M, Achiron R et al. "Prophylactic pelvic artery catheterization and embolization in women with placenta accreta: can it prevent caesarean hysterectomy?" American Journal of Perinatology, vol. 27, no. 6, pp. 455-461, 2010. View at Publisher - View at Google Scholar . View at Scopus. https://doi.org/10.1055/s-00301247599.

[16] Esh-Broder E, Ariel I, Abas-Bashir N, Bdolah $Y$ and HochnerCelnikiera $D$. Placenta accreta is associated with IVF pregnancies: a retrospective chart review. 2011.

[17] Oyelese $Y$ and Smulian JC. Placenta previa, placenta accreta, and vasa previa.ObstetGynecol; 2006; 107:927-41. https://doi.org/10.1097/01.AOG.0000207559.15715.98.

[18] Nguyen D, Nguyen C, Yacobozzi M, Bsat F and Rakita D. Imaging of the placenta with pathologic correlation.Semin Ultrasound CT MR. 2012; 33(1):65-77. https://doi.org/10.1053/j.sult.2011.10.003.

[19] Esh-Broder E, Ariel I, Abas-Bashir N, Bdolah Y and HochnerCelnikiera $D$. Placenta accreta is associated with IVF pregnancies: a retrospective chart review. 2011.

[20] (Belizan et al., 1999. Rates and implications of caesarean sections in Latin America : etiological study.

[21] Van der Voet LF1, Vervoort AJ, Veersema S, BijdeVaate AJ, Brölmann HA and Huirne JA. Minimally invasive therapy for gynaecological symptoms related to a niche in the caesarean scar: a systematic review. BJOG. 2014; 121(2):145-56.

[22] Stanton CK and Holtz SA. Levels and trends in caesarean birth in the developing world. Stud FamPlann 2006;37(1):41-8

[23] (Nicole et al, .2011) WU et al., 2005. Impact of multiple caesarean deliveries on maternal morbidity: a systematic review

[24] (Armstrong et al., (2004) Is placenta accreta catching up with us? Aust N Z J ObstetGynaecol. 2004;44(3):210-3.

[25] (Sivan et al., (2010) reported .Fergal, (2002). . "Prophylactic pelvic artery catheterization and embolization in women with placenta accreta: can it prevent caesarean hysterectomy?" American Journal of Perinatology, vol. 27, no. 6, pp. 455-461, 2010. View at Publisher . View at Google Scholar. View at Scopus

[26] Buhimschi CS, Buhimschi IA, Patel S Malinow AM and Weiner $\mathrm{CP}$. Rupture of the uterine scar during term labour : contractility or biochemistry ? BJOG . 2005;112(1): 38-42, Buhimschi CS, Buhimschi IA, Yu C, Wang H , Sharer DJ , Diamond MP, Petkova AP , Garfield RE, Saade GR and Weiner CP. The effect of dystocia and previous caesarean uterine scar on the tensile properties of the lower uterine segment . Am J Obstet Gynecol ; 2006 ; 194(3) : 873-883

[27] Spong CY and Queenan JT : Uterine scar assessment : how should it be done before trial of labor after caesarean delivery ? Obstet Gynecol 2011;117(3):521-522.

[28] Vikharvera Osser O and Valentin L. Clinical importance of appearance of caesarean hysterotomy scar at transvaginal ultrasonography in nonpregnant women . Obstet Gynecol ; 2011; 117(3):525-533.
[29] Esh-Broder E, Ariel I, Abas-Bashir N, Bdolah Y and HochnerCelnikiera D. Placenta accreta is associated with IVF pregnancies: a retrospective chart review. 2011.

[30] Uitto J. : The role of elastin and collagen in cutaneous aging : intrinsic aging versus photoexposure . J Drugs Dermatol ; 2008 ; 7(2 suppl) : s12-s16

[31] Yousem SA. Pulmonary apical cap . A distinctive but poorly recognized lesion in pulmonary surgical pathology . Am J Surg Pathol ; $2001 ; 25(5): 679-683$

[32] (Wehrum et al., 2011)Accreta complicating complete placenta previa is characterized by reduced systemic levels of vascular endothelial growth factor and byepithelial to mesenchymal transition of the invasive trophoblast .

[33] Tseng JJ , Chou MM, Hsieh YT, Wen MC, Ho ES and Hsu SL. Differential expression of vascular endothelial growth factor, placenta growth factor and their receptors in placentae from pregnancies complicated by placenta accreta . Placenta 2006;27:70-78

[34] Yang J , Lim YK ,Kim HS , Chang KH , Lee JP and Ryu HS .sonographic findings of placental lacunae and the prediction of adherent placenta in women with placenta previa totalis and prio caesarean section . Ultrasound Obstet Gynecol ; 2006 ; 28:178-82

[35] (Comstock CH, Love JJ Jr, Bronsteen RA, Lee W, Vettraino IM, Huang RR and Lorenz RP. Sonographic detection of placenta accreta in the second and third trimesters of pregnancy. Am J ObstetGynecol; 2004; 190: 1135-1140. 